\title{
Wies procedure combined with anterior lamellar recession in the management of cicatricial entropion of the upper eyelid
}

\author{
Sawsan A Shalaby \\ Ophthalmology department, Faculty of medicine (for Girls) Al Azhar University
}

\begin{abstract}
Purpose: To evaluate the efficacy of the Wies procedure combined with anterior lamellar recession in the management of cicatricial entropion of the upper eyelid.

Patients and methods: Nineteen patients (24 upper lids) with severe cicatricial entropion, trichiasis, and tarsal shortening were included in this study. Previous Snellen's operation was recorded in 6 patients (8 eyelids). All cases underwent anterior lamellar recession and wies procedure.
\end{abstract}

Results: No residual entropion (no lash-cornea touch) was recorded in all lids (100\%). All cases developed postoperative edema that subsided gradually within one week. Over correction occurred in 2 lids $(8.3 \%)$, and three eyelids developed infection (12.5\%), which healed in few days after antibiotic therapy. The mean follow up was 9 months (range; 6 to12 months).

Conclusion: Wies procedure combined with anterior lamellar recession in the management of cicatricial entropion of the upper eyelid are effective especially for recurrent cases and short tarsus; no lid shortening developed postoperatively, and gave cosmetically accepted results.

\section{Introduction:}

Cicatricial entropion of upper eye lid results from loss or scarring of the posterior lamella of the eye lid. Conjunctival scarring is the common denominator in cicatricial entropion. This cicatricial scarring may result from chronic blepharoconjunctivitis, trachoma, chemical injuries, trauma, chemical burns, any other acute or chronic inflammatory process, and systemic mucocutaneous disorders as ocular cicatricial pemphigoid (OCP), and Steven Johnson syndrome, SJS(Ei Ti et al, 2001, and El-sedfy et al, 2003).

The conventional procedures however, often don't affect a permanent cure and my produce unwanted complications. Thus surgical management is recommended. Surgical treatments have initial success but long-term results are poor and recurrences are frequent. a wide variety of operations have been described, some require grafts as Van Milligen's operation but it had many drawbacks such as sloughing of the graft, infection and recurrence(John et al,1992 and - Rubenzik et al, 1975). Other procedures included scleral graft, skin graft (Rubenzik et al, 1975 and Reacher et al, 1990), transverse tarsotomy and marginal rotation, and tarsal grooving (Snellen's operation) (Wu et al, 2010).

The WHO has approved the bilamellar tarsal rotation procedure (BTR). However, studies have shown that recurrence rates after surgery can be high (Kerie and Bejiga , 2010).

This study aim was to report the efficacy of the Wies procedure (transverse blepharotomy and marginal rotation) combined with anterior lamellar recession in the management of severe cicatricial entropion of the upper or lower eyelid.

\section{Patients and methods:}

This study was done in Al Zahraa University Hospital, in a period from September 2008 t o July 2010. It included, 24 upper eyelids for 19 patients (5 patients had surgery for both eyes), with severe cicatricial entropion and trichiasis 
Wies procedure...

with tarsal shortening. Severe entropion was defined to be present if there was lash globe contact in primary gaze, conjunctival scarring, and tarsal deformity (Kemp and Collin, 1986). Previous treatment was recorded in 13 patients (17 eyelids), Snellen's operation for 6 patients (8 eyelids), and electrolysis and/ or diathermy for 7 patients (9 eyelids), while 6 patients ( 7 eyelids) were primary and had fibrosis with short tarsus. All cases underwent anterior lamellar recession and Wies procedure (transverse blepharotomy and marginal rotation).

\section{With support of Groth (2003), the operation consisted of:}

1- Local infiltration an aesthesis

2- Splitting of the upper lid at grey line (just anterior to the orifices of meibomian glands), into anterior and posterior lamellae for $3 \mathrm{~mm}$. depth using super blade No.15.

3- Skin incision at the upper lid crease (3-4 $\mathrm{mm}$. from the lash line) from the lateral canthus to a point of $2 \mathrm{~mm}$. lateral to the punctum

4- Blunt splitting and retraction of orbicularis muscle (avoiding vascular injury), to expose the tarsal plate

5- Dissection on the anterior tarsal surface was carried superiorly into the space between Muller's muscle and levator aponeurosis and inferiorly into the lashes.

6- A full-thickness tarsal incision was made approximately $3 \mathrm{~mm}$ above the lash line.

7- Recession of anterior lamella for 2-3 mm.

8- Four 6-0 vicryl double armed sutures were passed through the superior attached tarsus to the marginal tarsus at the site of recession and the two needles exit at the skin near the cilia ( just above the lashes). The bared area of exposed tarsus was left to granulate and to heal.
9- Skin stitches were interrupted and included levator aponeurosis to reform upper lid Crease. The sutures were removed after 10 days.

Patients were followed on the first day, one week, two weeks, and monthly for at least 6 months.

\section{Results}

Twenty four upper lids of 19 patients were included in this study, 11 women and 8 men with a mean age of 52.6 years (range, $41-72$ years). Thirteen patients (17 lids) had recurrent entropion. All were diagnosed as cicatricial entropion (severe degree) and trichiasis that were followed up for a minimum of 6 months after surgery the mean follow up period was 9 months (range, 6 to 12 months).

A successful outcome was defined by Bleyen, and Dolman (2009), as no recurrence of the entropion or trichiasis and/or patient satisfaction at least 6 months postoperatively lid margin was restored to its position and no lash - glob contact with cosmetic acceptance (patients satisfaction), figure 1, 2 . All cases were successful cured (100\%), figure, 1 . Twenty two lids $(91.7 \%)$ were satisfied cosmetically, while the remained 2 $(8.3 \%)$ were unsatisfied due to overcorrection (figure, 2). No metablastic lashes posterior to the normal lash line were seen. No thickening of the lid margin was observed except for the overcorrected 2 cases $(8.3 \%)$ which were from the recurrent cases. Three eyelids developed infection $(12.5 \%)$ which healed in few days after antibiotic therapy. In the early postoperative period, all cases developed postoperative hyperemia of the exposed tarsus and edema of the lid that subsided gradually within one week (table,

1). 


\section{Sawsan Shalaby}

Table (1): Post operative results.

\begin{tabular}{|c|c|c|c|l|l|}
\hline $\begin{array}{c}\text { Success } \\
(\text { cure rate) }\end{array}$ & $\begin{array}{c}\text { Cosmetic } \\
\text { acceptance }\end{array}$ & Infection & $\begin{array}{c}\text { Over } \\
\text { correction }\end{array}$ & Recurrence & $\begin{array}{c}\text { Thickened } \\
\text { lid margin }\end{array}$ \\
\hline $\begin{array}{c}24 \text { eyelids } \\
(100 \%)\end{array}$ & $\begin{array}{c}22 \text { eyelids } \\
(91.7 \%)\end{array}$ & $\begin{array}{c}3 \text { eyelids } \\
(12.5 \%)\end{array}$ & $\begin{array}{c}2 \text { eyelids } \\
(8.3 \%)\end{array}$ & $\begin{array}{c}\text { Non } \\
(0.0 \%)\end{array}$ & $\begin{array}{c}2 \text { eyelids } \\
(8.3 \%)\end{array}$ \\
\hline \hline
\end{tabular}
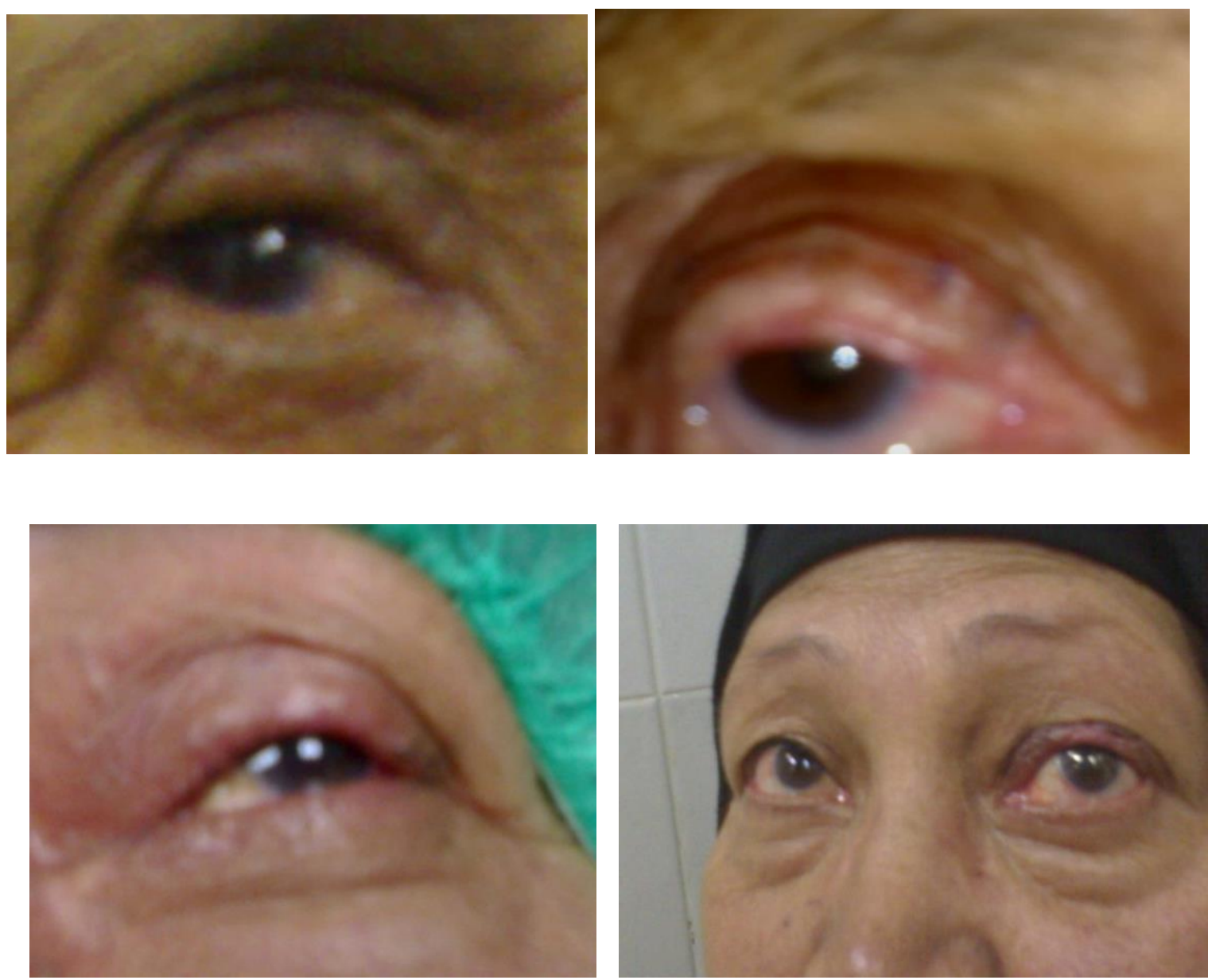

Figure (1): Top left; preoperative (convex tarsus due to entropion). Top right; postoperative straightened tarsus after correction of entropion. Bottom left; preoperative. Bottom right; post. 


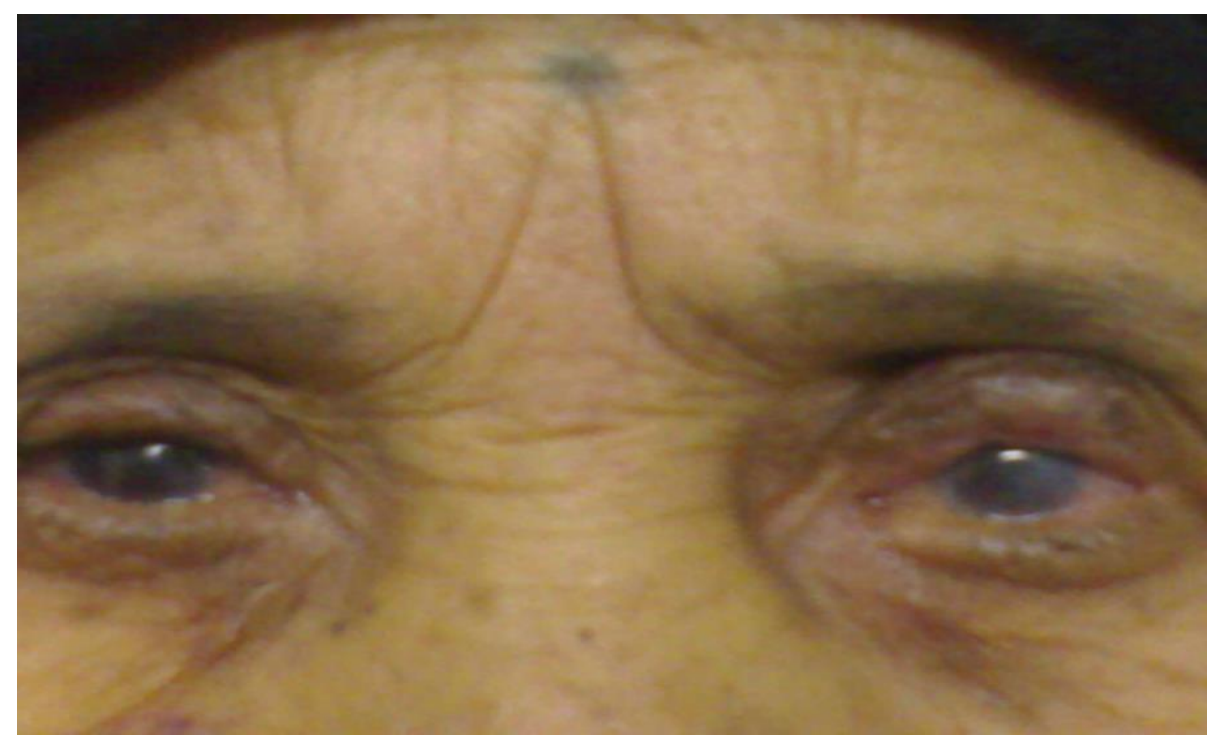

Figure (2): Bilateral postoperative follow up; Rt: successful. Lt: overcorrected

\section{Discussion}

In cicatricial entropion, the basic is correction of the lid margin malposition, which may be affected by shifting the anterior and posterior lamellae or lengthening the deficient posterior lamellae by tarsal fracture or tarsal substitute (Yaqub, and Leatherbarrow (1997), and Elder, and Collin, 1996).

Variable surgical techniques have been used for management of cicatricial entropion, with success rates ranging from $55 \%-94 \%$ in the study of Kersten et al, (1992). According to the etiology and severity of entropion, Success rates of transverse tarsotomy with lid margin rotation in the report of Kersten et al, (1992), was $94 \%$ for mild to moderate entropion, and $55 \%$ for severe cases and they recommend it as the initial procedure after which more techniques may be used. The overall success rate was $85 \%$ and $14 \%$ developed recurrences that required a second procedure. Wies procedures were repeated with second success. This was against the severe complications stated by Groth (2003). Higher rate of success $(100 \%)$ in this study can be attributed to combined anterior lamellar recession.

Combined procedures were reported with success $100 \%$. In this study, combined wies procedure with anterior lamellar recession was used with that rate, also Sayed (2002), had higher success $100 \%$ in combined tarsal marginal rotation with super advancement of posterior lamella in a study similar in technique and success rate of $100 \%$ to that of Seif et al (1999). Other techniques included; tarsal wedge resection (Snellen's operation), anterior lamellar reposition, anterior lamellar recession, bilamellar tarsal rotation (tarsotomy), tarsal margin rotation, posterior lamellar advance, and use of various types of grafts. Failure of these procedures is attributed to unsatisfactory for severe cases, shortening of tarsus, cosmetically unacceptable or because the progressing cicatrization process Seif et al (1999). Various grafting, add the complexity of the procedure and the repair, unpredicted viability of the graft and poor vascularity of these lids, with a risk of secondary infection or sloughing of the graft (Reacher et al, 1990).

The Wies procedure combined with anterior lamellar recession is reasonably successful in managing cicatricial entropion and trichiasis of upper eyelids especially severe, recurrent cases, and cases of short fibrosed tarsus.

\section{References}

Bleyen I, Dolman PJ.The Wies procedure for management of trichiasis or cicatricial entropion of either upper or lower eyelids. Br J Ophthalmol. 2009 Dec; 93(12):1612-5. 


\section{Sawsan Shalaby}

Ei Ti S, Tow S L C, and Phaik Chee S. Amniotic membrane transplantation in entropion surgery. Ophthalmology 2001; 108:1209-17

El-sedfy H O, Mohamed Wael A A, Soliman M,.Lamellar Division and Amniotic Membrane Graft in Management of Upper Lid entropion. BULL EGYPTIAN OPHTHALMOL SOC, 2003; 96, NUMBER 5

Elder MJ, Collin R. Anterior lamellar repositioning and grey line split for upper lid entropion in ocular cicatricial pemphigoid. Eye 1996; 10:439-42

Groth M J. Cicatricial entropion, oculoplastic surgery. In: Ophthalmic surgery principles and practice.Spaeth G L (ed.), 2003, volume 2; chapter 5:433-7

John W.S., Clinton D.M., and Jerry K.P.: Surgery of the eye lid. In Tasman W., and Jaeger A.E: Duane's clinical ophthalmology, Lipincott Company, Philadelphia, Volume 6, Chapter 123, 1992, P. 22-3

Kemp EG, Collin JRO. Surgical management of upper lid entropion Br J Ophthalmol 1986; 70:575-9

Kerie A, Bejiga A. Pattern of recurrence of trachomatous trichiasis after surgery in Enemor and Ener district, Central Ethiopia. '. Ethiop Med J. 2010 Oct; 48(4):301-8

Kersten RC, Kleiner, FP, Kulwin DR. Tarsotomy for treatment of cicatricial entropion with trichiasis. Arch Ophthalmol 1992; 110: 714-7
Reacher $\mathrm{MH}$, Huber MJE, Canangratnan $\mathrm{R}$ and Algassany A. A trial surgery for trichiasis of the upper eyelid from trachoma. Br. J. Ophthalmol. 1990; 74: 109-113.

Rubenzik R, Tenzel RR and Miller GR. Repair of cicatricial entropion of the upper eyelid. Am. J. Ophthalmol.1975; 80: 302-3.

Sayed A S. Tarsal margin rotation with posterior lamella super advancement for the treatment of Cicatricial Entropion Of The Upper Eyelid Due To Trachoma .BULL EGYPTIAN OPHTHALMOL SOC, 2002; 95, NUMBER 5

Seif SR, Carter SR, Tovilla JL and chooPH. Tarsal margin rotation with posterior lamella supper advancement for the management of cicatricial entropion of the upper eyelid. Am.J. Ophthalmol.1999; 127: 67-71.

Wu AY, Thakker MM, Wladis EJ, Weinberg DA.Eyelash resection procedure for severe, recurrent, or segmental cicatricial entropion. Ophthal Plast Reconstr Surg. 2010 Mar-Apr; 26(2):112-6.

Yaqub A, Leatherbarrow B. The use of autogenous auricular cartilage in the management of upper eyelid entropion. Eye 1997; 11:801-5 


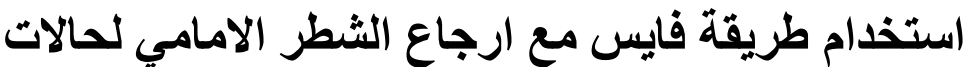 الالتفاف الاخلي التليفي للعين بالجفن العلوي التوي
}

\author{
قسم طب وجراحة العيون - كلية الطبب بنات - جامعة الأزهر
}

التفاف الجفن للاخل الناجم عن تلافات للطبقه الخلفيه للجفن غالبا مايسببه التهابات مزمنة ب بالجفن و الملتحمه .

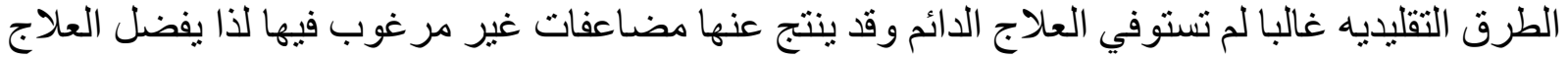
الجراحي وله انواع كثيرة

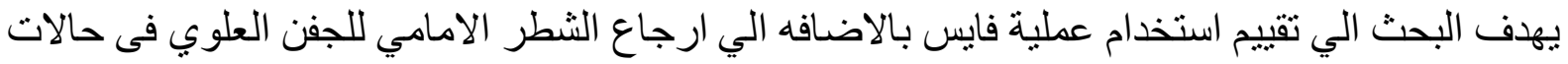

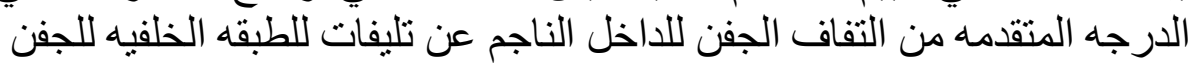

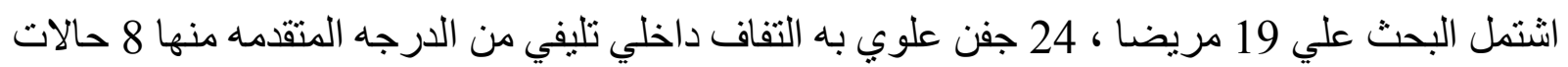

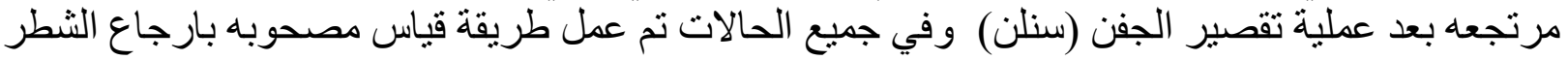

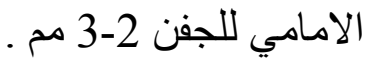

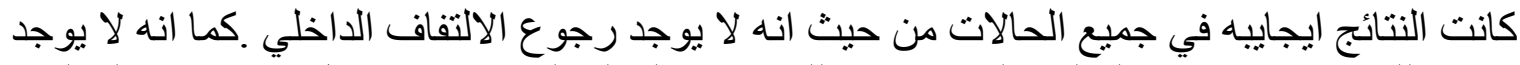

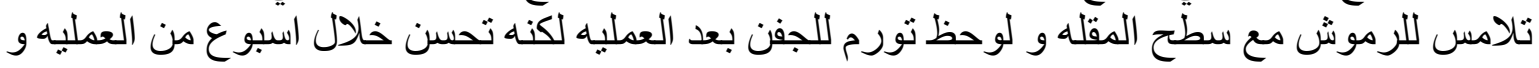

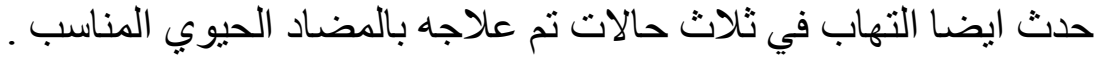

يخلص البحث الي ان استخدام الطريقتين معا فعال في معالجة الالتفاف الداخلي التليفي للجفن العلوي مع عدم

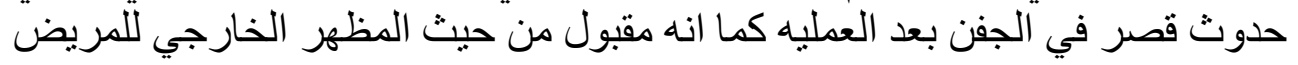

